See Article page 819.

\section{Commentary: Why do we operate in metastatic lung cancer?}

\section{Jessica S. Donington, MD, MSCR}

The concept of oligometastasis was introduced by Hellman and Weichselbaum nearly 50 years ago but was relatively rare in non-small cell lung cancer (NSCLC) until recently. ${ }^{1}$ Imaging advancements have increased the identification of small metastatic deposits and diagnosed more patients early in the metastatic spectrum. This has created new paradigms in the management of metastatic NSCLC; it is no longer appropriate to cluster all stage IV patients into a single cohort with a single treatment approach. Patients with oligometastatic disease have improved survival compared with those with widespread disease, and this prognostic heterogeneity is acknowledged in the 8th edition of the American Joint Committee on Cancer Lung Cancer staging system, which includes a M1b category for oligometastatic disease, defined by a single metastasis in a distant organ. ${ }^{2}$

Local consolidative therapy (LCT) is treatment directed at sites of known disease following systemic therapy, including the primary tumor and residual metastatic sites. Surgery and curative radiation therapy (external beam or stereotactic body radiotherapy) are the most common LCTs used in NSCLC, but the terminology also applies to percutaneous heat and cryo-based interventions. Much of the recent literature outlining the benefit of LCTs in oligometastatic NSCLC combines multiple treatment approaches, and no head-to-head comparisons of modalities exists. Surgery has been used in oligometastaic NSCLC for $>40$ years, with 5 -year survival ranging from $15 \%$ to $55 \%$. The oldest series describe the treatment of patients with isolated brain metastasis. ${ }^{3,4}$ Widespread adoption of surgery for oligometastatic diseases has been hampered by 2 main factors: (1) the retrospective nature of the data

From the Department of Surgery, University of Chicago Medicine, Chicago, Ill.

Disclosures: Dr Donington serves as an advisor and speaker for AstraZeneca, Roche/ Genentech, and BMS.

The Journal policy requires editors and reviewers to disclose conflicts of interest and to decline handling or reviewing manuscripts for which they may have a conflict of interest. The editors and reviewers of this article have no conflicts of interest.

Received for publication May 3, 2021; revisions received May 3, 2021; accepted for publication May 4, 2021; available ahead of print May 8, 2021.

Address for reprints: Jessica S. Donington, MD, MSCR, Department of Surgery, University of Chicago Medicine, 5841 S Maryland Ave, Room S-546/ MC 5047, Chicago, IL 60637 (E-mail: jdonington@uchicago.edu).

J Thorac Cardiovasc Surg 2022;163:826-7

0022-5223/\$36.00

Copyright $₫ 2021$ Published by Elsevier Inc. on behalf of The American Association for Thoracic Surgery

https://doi.org/10.1016/j.jtcvs.2021.05.002

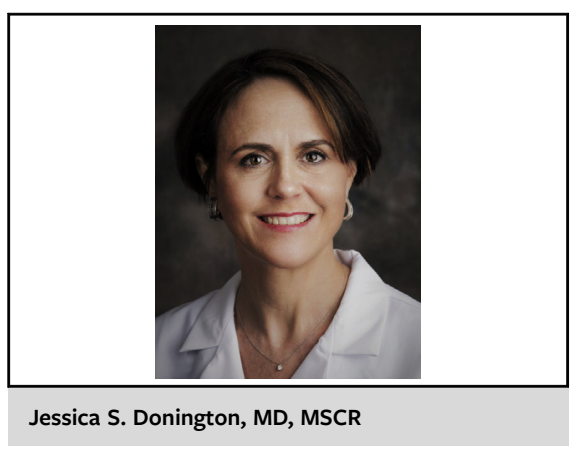

CENTRAL MESSAGE

Local consolidative therapy improves survival in select oligometastatic NSCLC patients. Thoracic resection is beneficial because of excellent local control, staging, and tissue acquisition provided.

and (2) attribution of any survival advantage to selection bias. These issues were debunked by 2 recent prospective trials from radiation oncologists. Each randomized patients with oligometastasis at the completion of first-line chemotherapy and showed significant survival advantage with LCT over supportive care. ${ }^{5,6}$ The details of these trials are outlined in the attached work for Isbell and Gomez. ${ }^{7}$ Many still believe that favorable biology is the primary driver of improved prognosis in the oligometastatic NSCLC and that small phase II trials do not prove benefit from LCT, but we are in an era in which LCTs carry minimal morbidity and mortality, and the lack of a randomized phase III evidence should not translate to denial of intervention in well-selected patients. Surgical resection of primary tumor needs to be recognized an important aspect of oligometastatic NSCLC treatment algorithms because of the exceptional local control and tissue acquisition provided by resection.

\section{References}

1. Hellman S, Weichselbaum RR. Oligometastases. J Clin Oncol. 1995;13:8-10.

2. Eberhardt WE, Mitchell A, Crowley J, Kondo H, Kim YT, Turrisi A III, et al. The IASLC lung cancer staging project: proposals for the revision of the M descriptors in the forthcoming eighth edition of the TNM classification of lung cancer. $J$ Thorac Oncol. 2015;10:1515-22.

3. Wronski M, Arbit E, Burt M, Galicich JH. Survival after surgical treatment of brain metastases from lung cancer: a follow-up study of 231 patients treated between 1976 and 1991. J Neurosurg. 1995;83:605-16. 
4. Nakagawa H, Miyawaki Y, Fujita T, Kubo S, Tokiyoshi K, Tsuruzono K, et al. Surgical treatment of brain metastases of lung cancer: retrospective analysis of 89 cases. J Neurol Neurosurg Psychiatry. 1994;57:950-6.

5. Gomez DR, Tang C, Zhang J, Blumenschein GR Jr, Hernandez M, Lee JJ, et al. Local consolidative therapy vs. maintenance therapy or observation for patients with oligometastatic non-small-cell lung cancer: long-term results of a multiinstitutional, phase II, randomized study. J Clin Oncol. 2019;37:1558-65.
6. Iyengar P, Wardak Z, Gerber DE, Tumati V, Ahn C, Hughes RS, et al Consolidative radiotherapy for limited metastatic non-small-cell lung cancer: a phase 2 randomized clinical trial. JAMA Oncol. 2018;4: e173501.

7. Isbell JM, Li BT, Gomez DR. The emerging role of local therapy in oligometstatic non-small cell lung cancer. J Thorac Cardiovasc Surg. 2022;163:819-25. 